УДК 543.421/.424:543.429.23:662.73.012

\title{
ОЦЕНКА ИЗМЕНЕНИЙ В СОСТАВЕ ФУЛЬВОКИСЛОТ ПОСЛЕ МЕХАНОАКТИВАЦИИ ТОРФА С ПОМОЩЬЮ МЕТОДОВ ИК- И ПМР-СПЕКТРОСКОПИИ
}

\author{
() А.А. Иванов", Н.В. Юдина, А.В. Савельева \\ Институт химии нефрти СО РАН, пр. Академический, 4, Томск, 634021 \\ (Poccuя), e-mail: ivanov@ipc.tsc.ru
}

С помощью методов ИК- и ПМР-спектроскопии показано, что при механоактивации торфа в структуре фульвокислот происходит перестройка, связанная с изменением количества функциональных групп в их составе - увеличивается количество кислородсодержащих групп и незамещенных алифатических структур. Кроме того, в результате механоактивации торфа повышается экстрактивный выход фульвокислот на 40-60 \%.

Ключевые слова: верховой торф, механолактивация, фульвокислоты, состав, ИК-, ПМР-спектроскопия.

\section{Введение}

О фульвокислотах (ФК) как одной из составляющих гуминовых веществ известно давно. Этот термин введен С. Оденом в 1919 г. для обозначения легкорастворимых органических соединений почвенного гумуса и заменивший термины «креновые» и «апокреновые» кислоты, которые остаются в щелочном растворе после осаждения гуминовых кислот (ГК); эти соединения имеют желтую или красновато-желтую окраску (лат. fulvus - красно-желтый, рыжий) [1,2]. В настоящее время не вызывает сомнений существование ФК как индивидуального класса органических соединений, образующихся в процессе гумификации и являющихся низкомолекулярной частью ГК [3].

С позиций коллоидной химии раствор ФК представляет собой слабодисперсную агрегативноустойчивую систему гуминовых веществ, мало зависящую от конщентраций, $\mathrm{pH}$ и ионной силы раствора $[3,4]$.

Коллоидно-химические свойства ФК во многом определяются особенностями химического строения их макромолекул. Они не компактны, а имеют рыхлое строение с хорошо развитой пористой структурой, в значительной степени характеризующая их водоудерживающую способность и сорбционные свойства $[5,6]$. Гидрофильные свойства ФК определяются соотношением в конденсированных ароматических системах углерода и боковых цепей, несущих гидрофильные группы $(-\mathrm{COOH},-\mathrm{OH})$. Строение ФК отличается меньшей ароматичностью в сравнение с ГК, значительным преобладанием алифатических заместителей. Качественный состав функциональных групп такой же, что и у ГК. ФК содержат больше функциональных

Иванов Александр Анатольевич - научный сотрудник, кандидат химических наук, тел.: (3822) 49-27-56, e-mail: ivanov@ipc.tsc.ru

Юдина Наталья Васильевна - заведующая

лабораторией, старший научный сотрудник, кандидат технических наук, тел.: (3822) 49-27-56,

e-mail: natal@ipc.tsc.ru

Савельева Анна Викторовна - научный сотрудник, кандидат биологических наук, тел.: (3822) 49-27-56, e-mail: anna@ipc.tsc.ru групп кислотной природы, в частности, карбоксильные и фенолгидроксильные, водород которых при определенных условиях замещается на метал [3, 7].

В целом, состав ФК изучен гораздо хуже, чем ГК, поэтому до сих пор нет достаточной ясности в отношении их структуры. Решение фундаментальной задачи их исследования сводится к применению экстракционных, химических, физико-химических. Использование механохимических превращений в

\footnotetext{
* Автор, с которым следует вести переписку.
} 
твердой фазе с целью разборки сложных макромолекул ФК является перспективным методом более глубокого их изучения [8].

Цель настоящей работы - изучить состав ФК верхового торфа до и после механоактивации с помощью методов ИК- и ПМР-спектроскопии.

\section{Экспериментальная часть}

В качестве объекта исследования использовались ФК, выделенные из верхового торфа месторождения «Темное» Томской области, отнесенные к моховой группе с низкой степенью разложения (5\%).

Механоактивацию (МА) торфа проводили в планетарной мельнице АГО-2С. Размер стальных шаров 8-10 мм, скорость вращения водило 1450 м/с. Время обработки - 2 мин. Модифицирование торфа проводилось без добавок и в присутствии твердой щелочи $3 \%$ мас. $\mathrm{NaOH}$.

Для препаративного получения ФК использовали принцип метода Форсита, когда кислый раствор пропускают через активированный уголь, промывают водой, затем снова растворяют адсорбированные кислоты раствором щелочи [3, 9]. После пропускания через Н-катионит и высушивания получают ФК.

Регистрацию ИК-спектров ФК проводили на ИК-Фурье спектрометре Nikolet 5700 с Raman модулем (корпорация Thermo Electron, США) в таблетках с KBr при соотношении 1:300 соответственно в интервале значений частоты от 400 до $4000 \mathrm{~cm}^{-1}$ с компенсацией сигналов адсорбированной воды. Для количественной оценки интенсивности полос поглощения применен метод базовых линий и относительных оптических плотностей [10].

Спектры ПМР регистрировали на ЯМР Фурье-спектрометре $A V A N C E A V 300$ (300мГц) фирмы Bruker (Германия) с использованием методики Фурье-преобразования с накоплением. Время накопления изменялось от нескольких часов до суток. Ширина развертки спектра составляла от -1 до 11 м.д. В качестве внутреннего стандарта использовали сигнал остаточных протонов дейтерорастворителя (ДМСО). Исследуемые образцы ФК растворяли в $0.1 \mathrm{M} \mathrm{NaOH} / \mathrm{D} 2 \mathrm{O}[11,12]$.

\section{Обсуждение результатов}

Как известно, механическое воздействие в присутствии реагентов приводит к изменению выхода и качественных характеристик основных компонентов торфов [8]. В таблице 1 представлены данные по изменению выходов ФК - в результате МА торфа повышается доступность и экстрактивность ФК.

Инфракрасные спектры специфических гуминовых веществ имеют характерный облик и постоянный набор полос поглощения, позволяющий отличить гуминовые вещества и, в частности, ФК от соединений других классов [4] (рис. 1).

Спектры ФК имеют широкие и интенсивные полосы поглощения около $3450 \mathrm{~cm}^{-1}$, обусловленные гидроксильными группами, полоса около $1720 \mathrm{~cm}^{-1}$, вызвана преимущественно карбоксильными группами $(\mathrm{C}=\mathrm{O}$ в $\mathrm{COOH}), 1600-1650 \mathrm{~cm}^{-1}$ проявляются полосы $\mathrm{C}=\mathrm{C}-$ связей алифатических и ароматических систем,

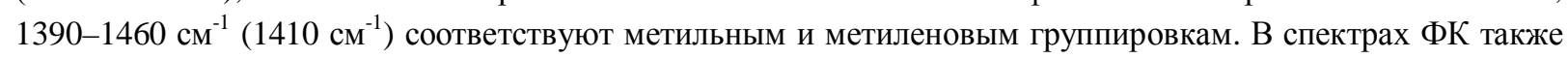
присутствуют полосы поглощения со слабой интенсивностью сигнала - 2930 и 1515 см$^{-1}$, которые соответствуют $\mathrm{CH}_{2}, \mathrm{CH}_{3}$ группам и $\mathrm{C}=\mathrm{C}$ (аром.). Последние служат дополнительным подтверждением ароматичности ФК. Сильное поглощение в области $1100 \mathrm{~cm}^{-1}$ обычно связывают с деформационными колебаниями гидроксильными ОН-спиртовыми группами.

По ИК-спектрам сложно судить о направленности механохимических превращений многокомпонентных систем. После механоактивации торфа интенсивность полос поглощения ФК возросла, что, в целом, говорит об увеличении количества функциональных групп в их составе (табл. 2).

Количественную оценку содержания

Таблица 1. Содержание ФК в торфе в зависимости от условий МА

\begin{tabular}{l|c}
\hline \multicolumn{1}{c|}{ Образец торфа } & $\begin{array}{c}\text { Содержание, \% масс. } \\
\text { на } 100 \text { г сухого торфа }\end{array}$ \\
\hline Исходный & 0,19 \\
МА без добавок & 0,32 \\
МА + 3\% NaOH & 0,24 \\
\hline
\end{tabular}

функциональных групп проводили на основании отношений оптических плотностей полос поглощения кислородсодержащих групп к оптическим плотностям, соответствующим ароматическим полисопряженным системам (1630 см-1), что позволяет судить о содержании в них гидрофильногидрофобных компонентов (табл. 2) [10]. 


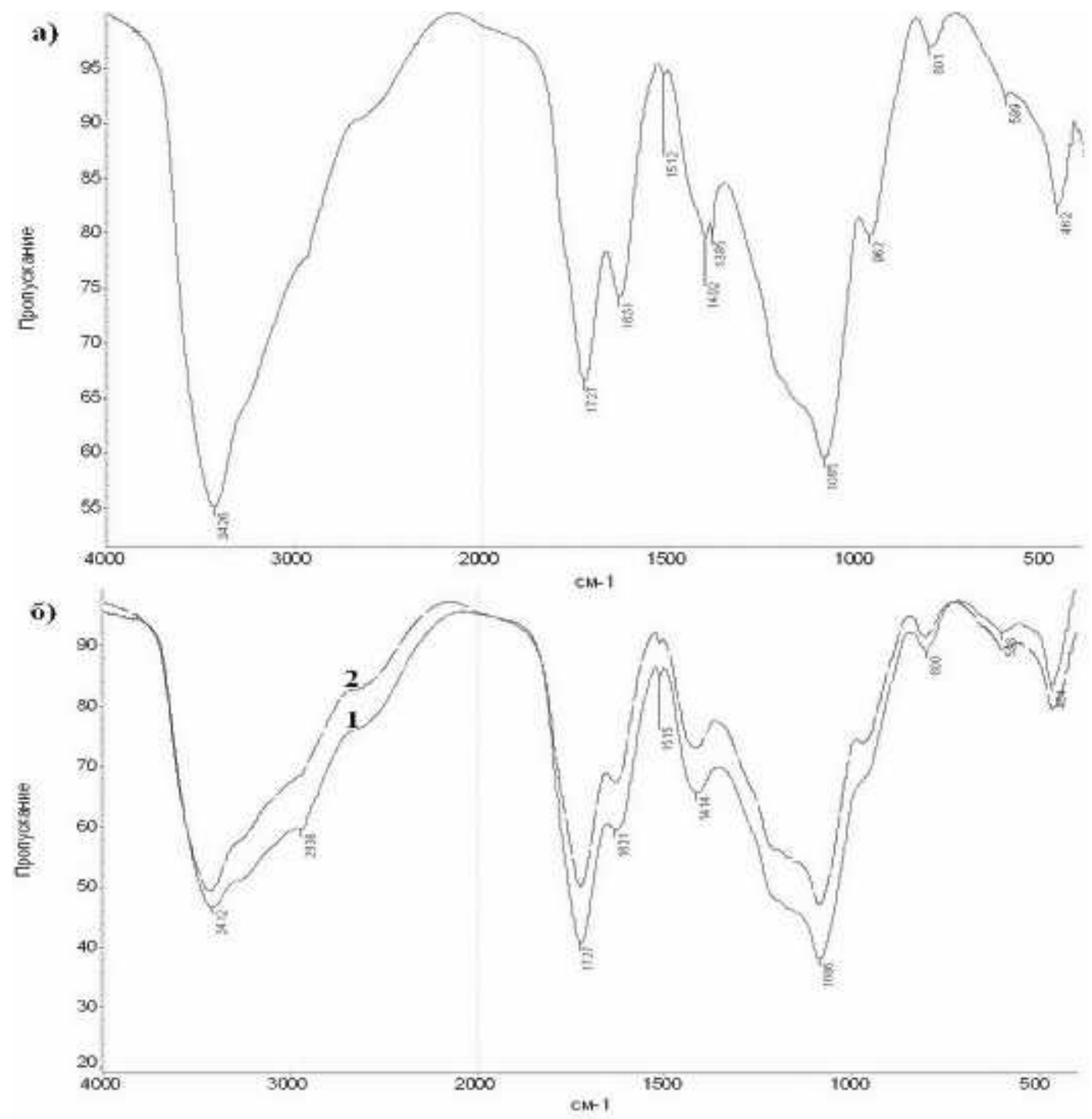

Рис. 1. ИК-спектры ФК: а) исходного, необработанного торфа; б) 1 - торфа, механоактивированного без добавок, 2 - торфа, механоактивированного в присутствии $3 \% \mathrm{NaOH}$

Таблица 2. Характеристика функционального состава ФК торфа по данным ИК-спектроскопии

\begin{tabular}{l|c|c|c|c|c|c|c|c}
\hline \multirow{2}{*}{ Образец ФК } & \multicolumn{4}{|c|}{ Интенсивность полос поглощения, см ${ }^{-1}$} & \multicolumn{3}{c}{$\begin{array}{c}\text { Соотншение оптических плотностей } \\
\text { полос поглощения }\end{array}$} \\
\cline { 2 - 9 } & 3450 & 1720 & 1630 & 1410 & 1080 & $3450 / 1630$ & $1720 / 1630$ & $1080 / 1630$ \\
\hline Исходного торфа & 0,260 & 0,178 & 0,130 & 0,100 & 0,226 & 2 & 1,37 & 1,74 \\
МА без добавок & 0,333 & 0,393 & 0,227 & 0,185 & 0,423 & 1,47 & 1,73 & 1,86 \\
МА+ 3\% NaOH & 0,285 & 0,279 & 0,155 & 0,121 & 0,303 & 1,84 & 1,8 & 1,95 \\
\hline
\end{tabular}

Анализ ИК-спектров показал, что механоактивация снижает соотношение 3450/1630, что может быть связано с повышением количества ароматических полисопряженных структур в молекулах ФК и снижением доли гидроксильных групп, связанных межмолекулярными водородными связями. Увеличение значений соотношений 1720/1630 и 1080/1630 указывает на значительное повышение содержания карбоксильных групп и спиртовых гидроксилов.

Данные, полученные с помощью ИК-спектроскопии, показывают, что МА торфа приводит к изменению состава ФК - увеличению кислородсодержащих функциональных групп (COOH- и OH-спиртовых групп), а наиболее выражены эти изменения у ФК торфа, механоактивированного без добавок.

Водород является вторым по значимости структурообразующим элементом ФК после углерода. Задача структурного исследования ФК методом ПМР спектроскопии сводится к выделению групп сигналов, по возможности относящихся к атомам водорода сходного структурного типа и их количественному анализу [13]. 
Для спектроскопии ПМР не существует проблемы регистрации количественных спектров ФК, но есть некоторые трудности, такие как присутствие в спектрах ПМР ФК сигналов остаточных протонов растворителя, перекрывающихся с малоинтенсивными сигналами протонов ФК. Существует проблема определения суммарной интегральной интенсивности протонов ФК. При регистрации спектров ФК в водных растворах в спектре наблюдаются только сигналы С-Н протонов. В связи с неизвестной общей интенсивностью сигналов протонов ФК в спектре возможно лишь определить их относительное содержание. Поэтому использование спектроскопии ПМР для анализа ФК ограничивается, в основном, определением распределения водорода углеродного скелета - соотношений количества ароматических, карбогидратных и алифатических протонов из спектров $\mathrm{D}_{2} \mathrm{O}$.

В спектрах ФК наблюдаются две хорошо разрешенные группы сигналов С-Н протонов, соответствующие алифатическим (0-6 м.д.) и ароматическим (6-9 м.д.) протонам, при этом интенсивность сигналов последних значительно ниже (рис. 2). В алифатической области спектра обычно выделяют диапазон химических сдвигов протонов О-замещенных алифатических фрагментов. Часть их относится к карбогидратным структурам (карбогидратные протоны) (3-5 м.д.) и протонов незамещенных алифатических структур (алифатические протоны) при 0-3 м.д. В водных растворах происходит быстрый в шкале времени ЯМР обмен подвижных протонов с дейтерием воды, все их сигналы сливаются с пиком $\mathrm{D}_{2} \mathrm{O}$ (HDO) (около 4,6 м.д.). В связи с этим невозможно их раздельное и даже суммарное определение. Поэтому определяют только распределение С-Н протонов в молекулах гумусовых кислот, в том числе и ФК $[13,14]$.

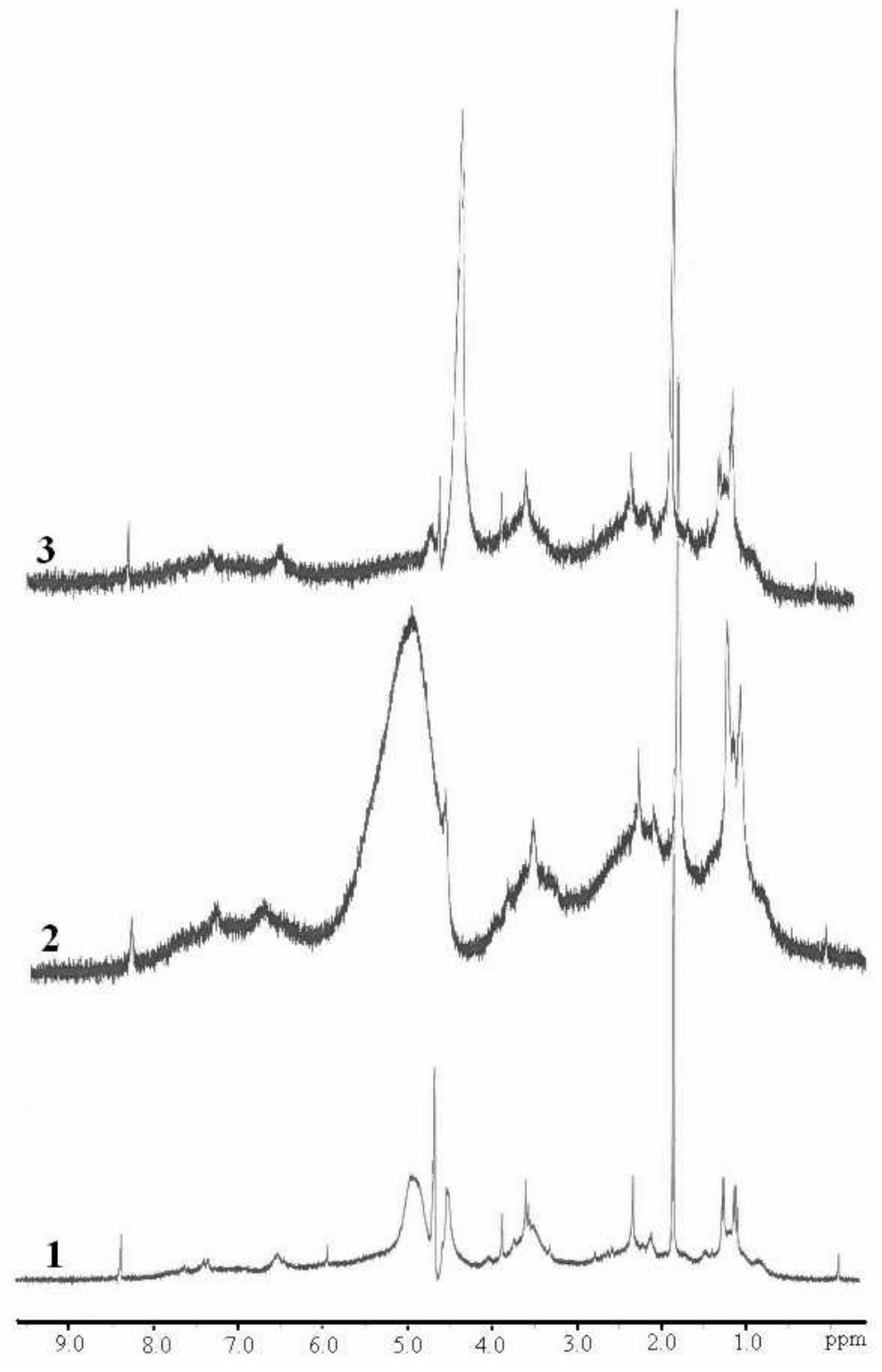

Рис. 2. ПМР-спектры ФК: а) исходного, необработанного торфа; б) 1 - торфа, механоактивированного без добавок, 2 - торфа, механоактивированного в присутствии $3 \% \mathrm{NaOH}$ 
Из таблицы 3 видно, что ФК исходного и механоактивированного торфа отличаются распределением водорода, связанного с углеродным скелетом молекул. Так, ФК исходного необработанного торфа характеризуются более высокими значениями соотношений Car-H/Calk-H и $\mathrm{CHn}-\mathrm{O} / \mathrm{CHn}$, а ФК торфа, механоактивированного без добавок и в присутствии щелочи, содержат меньше ароматических и алкоксильных (преимущественно метоксильных) протонов, что свидетельствует о высоком вкладе алкильных групп в состав углеродного скелета ФК.

\section{Заключение}

Таким образом, по результатам ИК- и ПМР-спектроскопии показано, что при МА торфа в ФК происходит структурная перестройка, связанная с изменением количества функциональных групп в их составе. Так, после МА торфа в составе ФК увеличивается количество кислородсодержащих функциональных групп, таких как $\mathrm{COOH}-$ и ОН-спиртовых групп, а изменение количества водородных атомов в углеродном скелете ФК указывает на повышение содержания незамещенных алифатических структур. Полученные данные позволяют расширить представления о структуре ФК и их механохимических превращениях.

\section{Список литературы}

1. $\quad$ Oden S. Humic Acids. Kolloidchem. Beih. 1919. 11. P. 75.

2. Орлов Д.С. Гуминовые вещества в биосфере // Соросовский образовательный журнал. 1997. №2. С. 56-63.

3. Александрова И.В. Органическое вещество почвы и процессы его трансформации. Л., 1980. 287 с.

4. Орлов Д.С. Химия почв. М., 1992. 259 с.

5. Лиштван И.И., Базин Е.Т., Гамаюнов Н.И., Терентьев А.А. Физика и химия торфа. М., 1989. 304 с.

6. Елин Е.С. Фенольные соединения в биосфере. Новосибирск, 2001. 392 с.

7. Околелова А.А. Природа и свойства фульвокислот // Почвоведение. 1992. №1. С. 65-68.

8. Иванов А.А., Юдина Н.В., Ломовский О.И. Влияние механохимической активации на состав и свойства гуминовых кислот торфов // Известия Томского политехнического университета. 2006. Т. 309. №5. С. 73-77.

9. Forsyth W.G.C. Studies on the more soluble complexes of soil organic matter // Biochem. J. 1947. Vol. 41, N2. Pp. 176-181.

10. Бабушкин А.А., Бажулин П.А., Королев Ф.А. и др. Методы спектрального анализа. М., 1962. С. $172-193$.

11. Ковалевский Д.В. Исследование структуры гуминовых кислот методами спектроскопии ЯМР ${ }^{1} \mathrm{H}$ и ${ }^{13} \mathrm{C}:$ дис. ... канд. хим. наук. М., 1998. 138 с.

12. Калабин Г.А., Каницкая Л.В., Кушнарев Д.Ф. Количественная спектроскопия ЯМР природного органического сырья и продуктов его переработки. М., 2000. 407 с.

13. Перминова И.В. Анализ, классификация и прогноз свойств гумусовых кислот : дис. ... д-ра хим. наук. М., 2000. $359 \mathrm{c}$.

14. Averett R.C., Leenheer J.A., McKnight. D.M., Thorn K.A. Humic substances in the Suwanne river, Georgia: Ineractions, properties, and proposed structures. U.S. 1994. Geological survey water-supply paper, 2373 p.

Поступило в редакиию 28 ноября 2012 2. 
Ivanov A.A. ${ }^{*}$, Yudina N.V., Savelyeva A.V. THE EVALUATION OF CHANGES IN THE COMPOSITION OF FULVIC ACID AFTER MECHANOACTIVATION OF PEAT BY METHODS OF IR- AND PMR-SPECTROSCOPY

Institute of petroleum chemistry SB RAS, Akademicheskiy avenue, 4, Tomsk, 634021 (Russia), e-mail: ivanov@ipc.tsc.ru

By methods of IR- and PMR-spectroscopy has showed that a reconstruction in the structure of fulvic acid after the mechanoactivation of peat associated with the change of functional groups in their composition - increases the number of oxygen-containing groups and unsubstituted aliphatic structures. Besides, an extractive yield of fulvic acids increases in 40-60\% as a result of mechanoactivation of peat.

Keywords: high-moor peat, mechanoactivation, fulvic acids, composition, IR-, PMR-spectroscopy.

\section{References}

1. Oden S. Humic Acids. Kolloidchem. Beih. 1919. 11. P. 75.

2. Orlov D.S. Sorosovskii obrazovatel'nyi zhurnal, 1997, no. 2, pp. 56-63. (in Russ.).

3. Aleksandrova I.V. Organicheskoe veshchestvo pochvy i protsessy ego transformatsii. [Soil Organic Matter and processes its transformation]. Leningrad, 1980, 287 p. (in Russ.).

4. Orlov D.S. Khimiia pochv. [Soil Chemistry]. Moscow, 1992, 259 p. (in Russ.).

5. Lishtvan I.I. Bazin E.T. Gamaiunov N.I., Terent'ev A.A. Fizika i khimiia torfa. [Physics and chemistry of peat]. Moscow, 1989, 304 p. (in Russ.).

6. Elin E.S. Fenol'nye soedineniia v biosfere. [Phenolic compounds in the biosphere.]. Novosibirsk, 2001, 392 p. (in Russ.).

7. Okolelova A.A. Pochvovedenie, 1992, no. 1, pp. 65-68. (in Russ.).

8. Ivanov A.A., Iudina N.V., Lomovskii O.I. Izvestiia Tomskogo politekhnicheskogo universiteta, 2006, vol. 309, no. 5, pp. 73-77. (in Russ.).

9. Forsyth W.G.C. Biochem. J., 1947, vol. 41, no. 2, pp. 176-181.

10. Babushkin A.A., Bazhulin P.A., Korolev F.A. Metody spektral'nogo analiza. [Methods of spectral analysis.]. Moscow, 1962, pp. 172-193. (in Russ.).

11. Kovalevskii D.V. Issledovanie struktury guminovykh kislot metodami spektroskopii IaMR $1 N$ i $13 S$ : dis. ... kand. khim. nauk. [Investigation of the structure of humic acids NMR spectroscopy 1H and 13C Dissertation of the candidate chemical sciences]. Moscow, 1998, 138 p. (in Russ.).

12. Kalabin G.A., Kanitskaia L.V., Kushnarev D.F. Kolichestvennaia spektroskopiia IaMR prirodnogo organicheskogo syr'ia i produktov ego pererabotki. [Quantitative NMR spectroscopy of natural organic material and its processing.]. Moscow, 2000, 407 p. (in Russ.).

13. Perminova I.V. Analiz, klassifikatsiia i prognoz svoisv gumusovykh kislot: dis. ... dok. khim. nauk. [Analysis, classification and prediction svoysv humic substances: the dissertation of the doctor of chemical sciences]. Moscow, 2000. 359 p. (in Russ.).

14. Averett R.C., Leenheer J.A., McKnight. D.M., Thorn K.A. Humic substances in the Suwanne river, Georgia: Ineractions, properties, and proposed structures. U.S. 1994. Geological survey water-supply paper, 2373 p.

Received November 28, 2012

\footnotetext{
* Corresponding author.
} 